\title{
Current and emerging therapies for the treatment of age-related macular degeneration
}

\author{
MVaughn Emerson \\ Andreas K Lauer \\ Casey Eye Institute, Oregon \\ Health and Science University, \\ Portland, OR, USA
}

Correspondence:Andreas K Lauer Mail code: CEI, 3375 S.W. Terwilliger Blvd, Portland, OR 97239-4I97, USA

$\mathrm{Tel}+$ I 5034948093

Fax + I 5034947233

Email lauera@ohsu.edu

\begin{abstract}
Age-related macular degeneration (AMD) is the leading cause of vision loss in the industrialized world. In the last few decades, the mainstay of treatment for choroidal neovascularization (CNV) due to AMD has been thermal laser photocoagulation. In the last decade, photodynamic therapy with verteporfin extended treatment for more patients. While both of these treatments have prevented further vision loss in a subset of patients, improvement in visual acuity is rare. Anti-vascular endothelial growth factor A (VEGF) therapy has revolutionized the treatment of AMD-related CNV. Pegaptanib, an anti-VEGF aptamer prevents vision loss in $\mathrm{CNV}$, although the performance is similar to that of photodynamic therapy. Ranibizumab, an antibody fragment and bevacizumab, a full-length humanized monoclonal antibody against VEGF have both shown promising results with improvements in visual acuity with either agent. VEGF trap, a modified soluble VEGF receptor analogue, binds VEGF more tightly than all other anti-VEGF agents and has also shown promising results in early trials. Other treatment strategies to decrease the effect of VEGF have used small interfering ribonucleic acid (RNA) to inhibit VEGF production and VEGF receptor production. Steroids, including anecortave acetate in the treatment and prevention of CNV, have shown promise in controlled trials. Receptor tyrosine kinase inhibitors, such as vatalanib, inhibit downstream effects of VEGF, and have been effective in the treatment of CNV in early studies. Squalamine lactate inhibits plasma membrane ion channels with downstream effects on VEGF, and has shown promising results with systemic administration. Other growth factors, including pigment epithelium-derived growth factor that has been administered via an adenoviral vector has shown promising initial results. In some patients ciliary neurotrophic factor is currently being studied for the inhibition of progression of geographic atrophy. Combination therapy has been investigated, and may prove to be more effective in the management of AMDassociated CNV. Ongoing and future studies will be crucial for optimizing the treatment of patients with AMD.
\end{abstract}

Keywords: age related macular degeneration, macular degeneration, VEGF, VEGF antagonist, anti-VEGF, choroidal neovascularization

\section{Introduction}

In 2002, the World Health Organization estimated there were 161.2 million visually impaired people in the world; 14 million (8.7\%) of whom had age-related macular degeneration (AMD) (World Health Organization 2007). In industrialized countries, AMD is the leading cause of adult vision loss. Choroidal neovascularization (CNV) is responsible for approximately $90 \%$ of the cases of severe vision loss due to AMD, and geographic atrophy (GA) is responsible for the remaining 10\% (Eye Diseases Prevalence Research Group 2004; Klein et al 2006). In 2004, the estimated prevalence of AMDrelated CNV in industrialized countries was $1.02 \%$ for people over the age of 40 years, and $8.18 \%$ for people over the age of 80 years (Eye Diseases Prevalence Research Group 2004). The magnitude of this problem has driven enormous research efforts 
regarding the prevention and treatment of AMD-related CNV and GA. Until recently, laser photothermal and photodynamic therapy have been the only treatments that have demonstrated benefit in large controlled clinical trials for the management of AMD-related CNV. For some patients with dry AMD, the use of oral micronutrient supplementation has reduced the rate of disease progression. Better understanding of the pathophysiologic mechanisms of AMD-related CNV and GA has allowed for the recent emergence of pharmacotherapy as a more targeted treatment approach toward both conditions.
This article reviews the current level of understanding regarding several of these new treatments for AMD-related CNV and GA (Table 1).

\section{Dry age-related macular degeneration and geographic atrophy}

Dry AMD includes the spectrum of findings from minimal drusen through geographic atrophy (GA), so long as no evidence of neovascularization is present. For patients with

Table I Current status of therapy for dry and wet age-related macular degeneration ${ }^{\mathrm{a}}$

\begin{tabular}{|c|c|c|c|}
\hline Therapeutic modality & $\begin{array}{l}\text { Supporting studies } \\
\text { [references in text] }\end{array}$ & Level of evidence & Notes \\
\hline $\begin{array}{l}\text { Antioxidant micronutrient } \\
\text { supplementation }\end{array}$ & AREDS $^{b}$ & Phase III study & $\begin{array}{l}\text { Odds ratio } 0.73 \text { for } \geq 3 \text { lines vision loss } \\
\text { at } 5 \text { years. }\end{array}$ \\
\hline Argon laser photocoagulation & MPSc & Phase III studies & $\begin{array}{l}45 \% \text { risk reduction of } \geq 6 \text { lines vision } \\
\text { loss at } 3 \text { years }\end{array}$ \\
\hline $\begin{array}{l}\text { Photodynamic therapy with } \\
\text { verteporfin }\end{array}$ & TAP, ${ }^{\mathrm{d}} \mathrm{VIP}$ & FDA approved & $\begin{array}{l}42 \% \text { risk reduction of } \geq 3 \text { lines vision } \\
\text { loss at } 2 \text { years }\end{array}$ \\
\hline Pegaptanib & VISION & FDA approved & $\begin{array}{l}33 \% \text { risk reduction of } \geq 3 \text { lines vision } \\
\text { loss at I year }\end{array}$ \\
\hline Ranibizumab & $\begin{array}{l}\text { ANCHOR, }{ }^{8} \text { MARINA, }{ }^{\text {h }} \text { PIER, } \\
\text { PrONTO' }\end{array}$ & FDA approved & Gain of 6.6 letters at 2 years \\
\hline Bevacizumab & Case series ${ }^{k, l, m, n, o}$ & CATT (phase III) in planning stage & Gain of $15-30$ letters $^{p}$ \\
\hline VEGF trap & CLEAR IT-I I & $\begin{array}{l}\text { Phase I; CLEAR-AMD (phase II) in } \\
\text { enrolment }\end{array}$ & Gain of 4.8 letters at 6 weeks \\
\hline Bevasiranib & CARE $^{r}$ & Phase II & Loss of 4.9-6.9 letters at 12 weeks \\
\hline Sirna-027 & Sirna $^{s}$ & Phase I; phase II in enrolment & Reasonable side-effect profile \\
\hline Vatalanib & $\mathrm{ADVANCE}^{\mathrm{t}}$ & Phase I; phase I/II in enrolment & Reasonable side-effect profile \\
\hline AdPEDF.II & $\mathrm{GenVec}^{\mathrm{u}}$ & Phase I; phase lb in data collection & Reasonable side-effect profile \\
\hline Squalamine lactate & Squalamine $^{v}$ & Phase I/II; Phase III in enrolment & Gain of $\geq 3$ lines in $26 \%$ \\
\hline Anecortave acetate & C-0I-99w & Phase III & No benefit over verteporfin \\
\hline
\end{tabular}

${ }^{\text {a}}$ For details and abbreviations of study names, please see manuscript text.

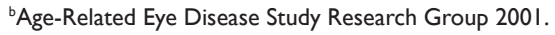

'Macular Photocoagulation Study Group 1986.

${ }^{\mathrm{d}}$ Treatment of Age-related Macular Degeneration with Photodynamic Therapy (TAP) Study Group $200 \mathrm{I}$.

eTreatment of Age-related Macular Degeneration with Photodynamic Therapy (TAP) Study Group 2003.

fKeyt 1996.

gHeier, Boyer, et al 2006.

hRosenfeld 2006a.

'Brown 2006.

iSchmidt-Erfurth 2007.

kHurwitz 2004.

'Moshfeghi 2006

mSpaide 2006.

nRich 2006.

^Avery 2006.

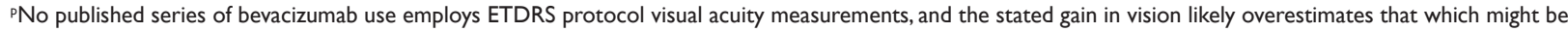
obtained by more rigorous vision testing methods.

qNguyen 2006.

rNguyen 2006.

sTolentino 2006.

toondeph 2006.

uImai 2005.

'Ciulla 2003 (Genaera has abandoned this product and is no longer in clinical development).

wKaiser 2007. 
mild disease, such as extensive small drusen $(\leq 63 \mu \mathrm{m}$ in diameter) or nonextensive intermediate size drusen $(>63 \mu \mathrm{m}$, $\leq 125 \mu \mathrm{m}$ ), the risk of losing vision or developing $\mathrm{CNV}$ or GA over 5 years is relatively low, at 1.3\% (Age-Related Eye Disease Study Research Group 2001). At the other end of the dry spectrum, GA occurs when areas of the retinal pigment epithelium (RPE) gradually disappear resulting in growing and coalescing areas of total RPE atrophy. Absence of the RPE leads to fallout of underlying choriocapillaris and overlying photoreceptors and affected areas correspond to scotomata (Spraul et al 1996).

\section{Antioxidant therapy}

The only therapy with proven benefit in patients with dry AMD is a combination of oral antioxidant supplements, containing vitamin $\mathrm{C}(500 \mathrm{mg})$ and vitamin E (400 IU), beta-carotene (15 mg, often labelled as equivalent to 25,000 IU of vitamin A); and zinc as zinc oxide (80 mg) and copper as cupric oxide (2 mg) (Age-Related Eye Disease Study Research Group 2001). This study found that patients with the intermediate (extensive intermediate size drusen or at least 1 large size druse $(\geq 125 \mu \mathrm{m}))$ or advanced (CNV or central GA in 1 eye) stages of AMD experience a statistically significant reduction in the 5-year rate of moderate vision loss, and progression to $\mathrm{CNV}$ or central GA. Therefore, the AREDS formula is recommended for those patients with the intermediate stage of AMD or worse, unless there are contraindications to the use of these oral micronutrient supplements. Copper was added to the AREDS formulations containing zinc to prevent copper deficiency anaemia, a condition associated with high levels of zinc intake.

Because the effects of high-dose beta-carotene are harmful in some patient populations, including smokers (Alpha-Tocopherol, Beta Carotene Cancer Prevention Study Group 1994), and the AREDS formula did not include other potentially beneficial micronutrients; the AREDS Research Group is currently enrolling a second trial (AREDS2) to investigate alternatives to the original AREDS formula. AREDS2 will address the role of omega-3 fatty acids and lutein as well as decreased dosages of beta-carotene in patients with intermediate or advanced AMD.

Although oral antioxidant supplementation helps prevent vision loss, local delivery of antioxidants is an area of current interest because a small but significant increase in the rate of hospitalization for urinary tract infections, among other conditions, has been reported (Age-Related Eye Disease Study Research Group 2001). The National Eye Institute is sponsoring a phase II trial of an antioxidant OT-551 (Othera Pharmaceuticals, Inc., Exton, PA), a low molecular weight compound metabolized to TP-H, which is a potent freeradical scavenger (National Institute of Health 2007). The study drug is administered topically as a drop three times daily in patients with bilateral GA, the progression of which will be assessed over a 2-year period.

\section{Anecortave acetate}

Anecortave acetate $\left(\right.$ Retaane $^{\circledR}$, Alcon Research, Ltd., Fort Worth, TX, USA), is an angiostatic steroid that does not exhibit glucocorticoid receptor-mediated activity. Its use in ocular disease is attractive because of its dosing and delivery: $15 \mathrm{mg}$ delivered as a posterior juxtascleral depot every 6 months. Because of its favourable dosing schedule and delivery and low risk profile, anecortave acetate is being studied in the Anecortave Acetate Risk Reduction Trial (AART) for the prevention of CNV in patients with eyes at high risk of converting from non-neovascular to neovascular AMD. This study targets patients with bilateral large size drusen and pigment changes who have a particularly high 5-year risk of progression to advanced AMD (47\%) based on the AMD simplified severity scale (Ferris et al 2005).

\section{Age-related macular degeneration- related choroidal neovascularization}

In choroidal neovascularization anomalous choroidal vessels grow under or through the RPE (Green et al 1993). Although specific stimuli for CNV growth remain unknown, it generally occurs in the presence of soft drusen, breaks in Bruch membrane, and a pro-inflammatory and pro-angiogenic milieu, characterized by elevated levels of vascular endothelial growth factor A (VEGF) or plateletderived growth factor (PDGF) (Ambati et al 2003).

Choroidal neovascularization has various patterns and configurations of proliferation that have been described based on its appearance with fluorescein angiography (FA). This highly useful diagnostic test allows one to determine the pattern, boundaries, composition and location of the neovascular lesions with respect to the centre of the fovea. These patterns of fluorescence have been shown to be reliable and reproducible in multi-centre clinical trials and in practice (Macular Photocoagulation Study Group 1982; Macular Photocoagulation Study Group 1986; Macular Photocoagulation Study Group 1991; Macular Photocoagulation Study Group 1993; Macular Photocoagulation Study Group 1994; Treatment of Agerelated Macular Degeneration with Photodynamic Therapy 
(TAP) Study Group 2001; Treatment of Age-related Macular Degeneration with Photodynamic Therapy (TAP) Study Group 2003). Classic CNV refers to a discrete, welldemarcated focal area of hyperfluorescence seen during the early images of the FA that increases in the intensity of fluorescence as the FA images progress in the later phases. The hyperfluorescence not only increases in intensity but also extends beyond the boundary of the initial lesion seen in the early FA images. Occult $C N V$ refers angiographic patterns lacking the features of classic $\mathrm{CNV}$ and is characterized by stippled or speckled hyperfluorescence that is frequently seen in the mid to later FA images. Occult CNV has been divided in to two types, fibrovascular pigment epithelial detachment(FVPED) and late leakage of an undetermined source(LLUS). In FVPED, the lesion has ophthalmoscopic or photographically appreciable thickness or elevation when viewed stereoscopically. The stippled hyperfluorescence may become well defined in the later FA images. In LLUS, the lesion is not elevated when viewed stereoscopically. The choroidal based stippled or speckled hyperfluorescence appears in the mid to late FA images and have no classic or FVPED angiographic qualities. CNV are also described by location. In subfoveal CNV, any component of the lesion resides underneath the geometric centre of the fovea. In extrafoveal $\mathrm{CNV}$ the edge of the lesion is no closer that 200 micrometers from the foveal centre. Those lesions whose edges reside within 1-199 micrometers from the foveal centre are juxtafoveal (Macular Photocoagulation Study Group 1991). When at least $50 \%$ of a choroidal neovascular lesion's composition is of a particular pattern, the qualifier predominantly is applied, as in predominantly classic, predominantly occult, or predominantly hemorrhagic. When less that $50 \%$ of a choroidal neovascular lesion's composition is of a particular pattern, the term minimally is applied, as in minimally classic (Treatment of Age-related Macular Degeneration with Photodynamic Therapy (TAP) Study Group 2003).

Natural history data have indicated that $62 \%$ of eyes with predominantly classic subfoveal CNV lose 3 or more lines of visual acuity at 2 years with $30 \%-48 \%$ losing 6 or more lines (Macular Photocoagulation Study Group 1993). The prognosis for eyes with CNV that does not involve the centre of the fovea is slightly worse, with $49 \%-62 \%$ losing 6 or more lines at 3 years, likely due to better visual acuity at baseline (Macular Photocoagulation Study Group 1986; Macular Photocoagulation Study Group 1994). Visual acuity outcomes are worse for eyes with larger lesions but are slightly better for eyes with occult angiographic patterns
(Treatment of Age-related Macular Degeneration with Photodynamic Therapy (TAP) Study Group 2003). Since poor visual outcomes occur without treatment, the prompt administration of safe and effective therapy is paramount in the management of $\mathrm{CNV}$ due to AMD.

\section{Thermal laser photocoagulation}

The Macular Photocoagulation Study (MPS) compared focal thermal laser photocoagulation of choroidal neovascularization to observation for $\mathrm{CNV}$ in AMD patients and consisted of multiple randomized clinical trials. Within 1 year of treatment, $25 \%$ of eyes with extrafoveal CNV due to AMD had lost fewer than 6 lines of vision with laser compared to $60 \%$ of eyes in the observation group (Macular Photocoagulation Study Group 1982), with a difference that persisted through 3 years (Macular Photocoagulation Study Group 1986). Two years after treatment, $21 \%$ of eyes with subfoveal CNV lost 6 or more lines of vision compared to $38 \%$ of eyes in the observation group (Macular Photocoagulation Study Group 1991). Unfortunately, eyes lasered for subfoveal CNV initially experience a marked drop in vision due to damage to the macular centre from photocoagulation. This undesirable effect and the advent of newer treatment options, make thermal laser photocoagulation a seldom-used treatment for patients with subfoveal CNV. Today, MPSstyle thermal laser photocoagulation for extrafoveal CNV is still considered an effective method of treatment and is used in selected cases.

\section{Photodynamic therapy with verteporfin}

Photodynamic therapy (PDT) involves an intravenous infusion of a photosensitizing agent that selectively binds to the increased number of lipoprotein receptors on the endothelium of abnormal vessels including CNV. The photosensitizing agent is then activated with laser light, usually in the far-red spectrum where light transmission through tissue and blood is higher. Activation of the photosensitizer, which is usually structurally related to porphyrin, results in free-radical formation, endothelial damage, and clotting cascade activation with thrombosis of the affected, abnormal vasculature. Verteporfin ${ }^{\circledR}$ (Visudyne, Novartis AG, Basel Switzerland) was the first photosensitizer approved for use in exudative AMD. It is administered at a dose of $6 \mathrm{mg} / \mathrm{m}^{2}$ and is activated by 689-691 nanometer laser light. The Treatment of Age-related Macular Degeneration with Photodynamic Therapy (TAP) study demonstrated a particular treatment benefit for patients with predominantly classic subfoveal CNV. At 2 years, PDT with verteporfin 
prevented loss of 3 or more lines of vision in $67 \%$ of these patients, compared to $39 \%$ of controls (Treatment of Agerelated Macular Degeneration with Photodynamic Therapy (TAP) Study Group 2001). However, 33\% of patients still lost 3 or more lines of vision over 2 years. In addition, it has been observed that PDT with verteporfin initiates an inflammatory response and up regulates VEGF and other growth factors that contribute to recurrence of CNV (Schmidt-Erfurth et al 2003). As such PDT with verteporfin is not currently preferred as monotherapy for the management of AMDrelated $\mathrm{CNV}$.

\section{VEGF-binding agents}

The vascular endothelial growth factor family consists of seven members (vascular endothelial growth factors A through $\mathrm{F}$, and placental growth factor), which are secreted polypeptides that share common structural domains but have different biological and physical properties (Ferrara 2004). VEGF plays a role in normal and pathologic angiogenesis and has at least six known isoforms which are formed through alternative splicing and are named based on their number of amino acids: 121, 145, 165, 183, 189, and 206 (Ferrara 2004). VEGF165 is a potently pro-angiogenic molecule that has been shown to effect retinal vascular proliferation and increased vascular permeability in the eye (Adamis et al 2005). Neovascular membranes in patients with AMD contain both isoforms VEGF165 and VEGF121 (Rakic et al 2003). The 165 isoform can be cleaved by plasmin to form the 110 amino acid fragment (VEGF110) that retains biologic activity (Keyt et al 1996). Animal models have also suggested that VEGF165 plays a role in inflammation, induction of leukocyte recruitment, and neuroprotection against ischemic injury (Nishijima et al 2007). This suggests that VEGF blockade may have both deleterious and salubrious effects in eyes with vascular disease. VEGF modulation has therefore been a target of many CNV treatments (Figure 1).

\section{Pegaptanib}

The first available anti-VEGF treatment for use in the eye was pegaptanib (Macugen ${ }^{\circledR}$, Eyetech Pharmaceuticals, Inc., New York, NY, USA), an aptamer that targets VEGF165. In the VEGF Inhibition Study in Ocular Neovascularization Clinical Trial (VISION), pegaptanib was shown to be safe and effective in preventing vision loss in patients with AMDrelated $\mathrm{CNV}$ for over 2 years when compared to controls (Gragoudas et al 2004). However, visual decline occurred over time in a pattern similar to that seen with PDT with verteporfin. This persistent loss of vision despite treatment with pegaptanib may be due to its selective binding to VEGF165 only, leaving all other isoforms uninhibited and available to stimulate neovascularization. Furthermore, its dosing of intravitreal injections every 6 weeks, compared to the less-invasive quarterly dosing schedule of PDT with verteporfin gave pegaptanib treatment of neovascular AMD no competitive advantage.

\section{VEGF antibodies and antibody fragments}

Both bevacizumab (Avastin ${ }^{\circledR}$, Genentech, Inc., South San Francisco, CA, USA), a full-length humanized antibody against VEGF, and ranibizumab (Lucentis ${ }^{\circledR}$, Genentech, Inc.), a humanized antigen-binding fragment against VEGF, are able to bind and inhibit all isoforms of VEGF (Ferrara et al 2004). Although ranibizumab has one binding site for VEGF compared to bevacizumab's two, ranibizumab has been affinity matured, exhibiting 3- to 6-fold higher affinity for VEGF than bevacizumab (Presta et al 1997; Chen et al 1999).

Ranibizumab is the first therapy for neovascular AMD to result in a significant improvement in visual acuity (Heier et al 2006). Two phase III studies of the use of monthly intravitreal injections of ranibizumab, MARINA and ANCHOR have been completed (Brown et al 2006; Rosenfeld et al 2006a). MARINA evaluated 716 patients with minimally classic or occult neovascular AMD. At 2 years, MARINA demonstrated a mean gain of 5.4 letters $(0.3 \mathrm{mg}$ group) to 6.6 letters ( $0.5 \mathrm{mg}$ group) for patients treated with monthly ranibizumab injections compared to a mean loss of 14.9 letters for patients undergoing monthly sham injections (Rosenfeld et al 2006a). ANCHOR evaluated 423 patients with predominantly classic neovascular AMD. At 1 year, ANCHOR demonstrated a mean gain of 8.5 letters $(0.3 \mathrm{mg}$ group) to 11.3 letters ( $0.5 \mathrm{mg}$ group) for patients treated with monthly ranibizumab injections compared to a mean loss of 9.5 letters for patients treated with verteporfin every 3 months (Brown et al 2006). The $0.5 \mathrm{mg}$ dose prevented 3 lines of vision loss in $90 \%$ (MARINA) to $96.4 \%$ (ANCHOR) compared to sham $(52.9 \%)$ or verteporfin $(64.3 \%)$. The $0.5 \mathrm{mg}$ dose resulted in 3 or more lines of vision gain in $33.8 \%$ (MARINA) to $40.3 \%$ (ANCHOR) compared to sham $(5.0 \%)$ or verteporfin $(5.6 \%)$. All comparisons were statistically significant $(\mathrm{p}<0.001)$. Serious adverse events for patients treated with ranibizumab included endophthalmitis (1\% (MARINA) to $1.4 \%$ (ANCHOR)) and uveitis $(0.7 \%$ (ANCHOR) to $1.3 \%$ (MARINA)). Arterial thromboembolic events occurred in $3.8 \%$ of the sham group compared to $4.6 \%$ in each of the ranibizumab groups (MARINA), and $2.1 \%$ of the verteporfin group compared to $2.2 \%$ (0.3 $\mathrm{mg}$ group) and 


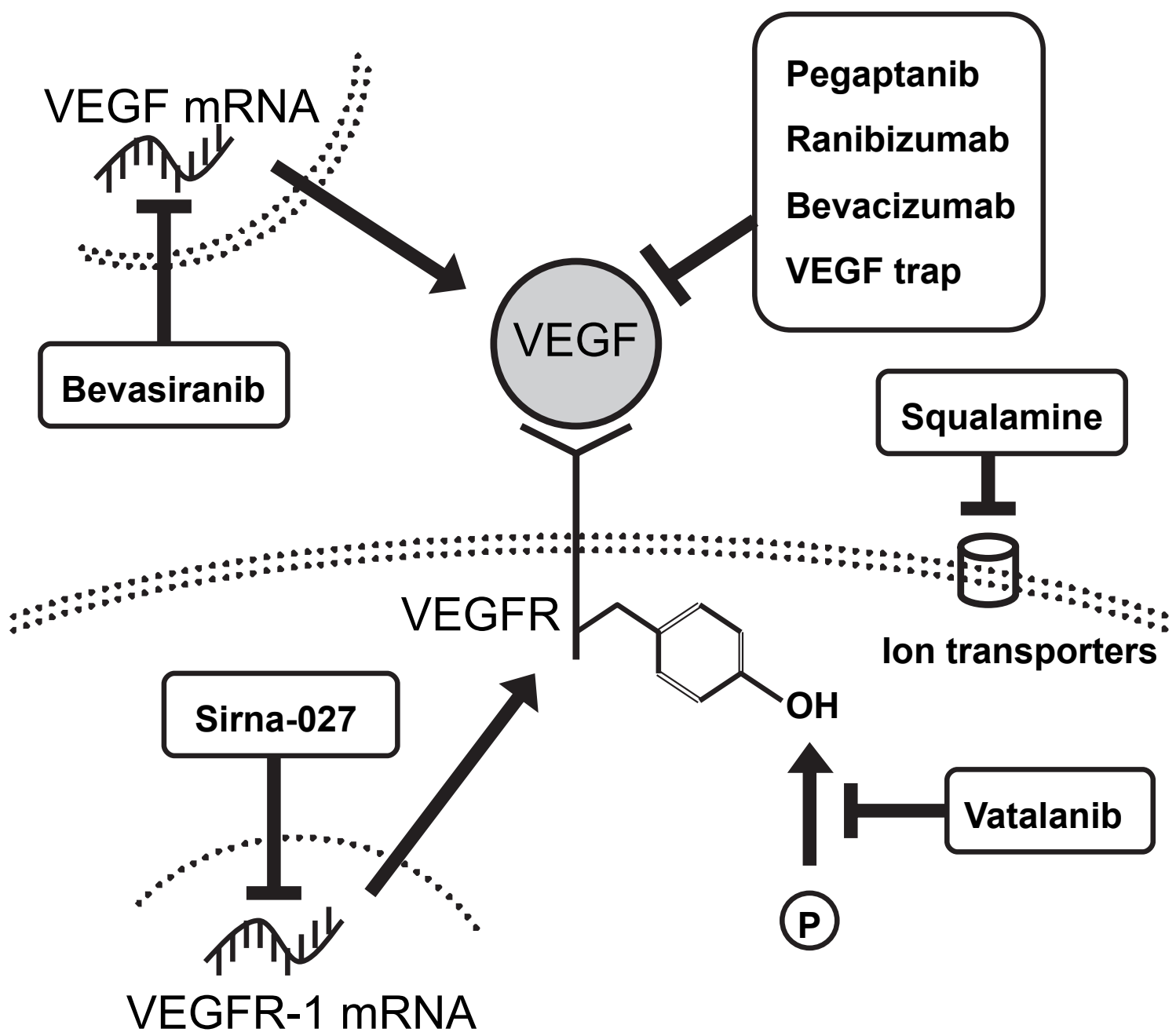

Figure I Mechanisms of inhibition of vascular endothelial growth factor-A (VEGF). Pegaptanib, ranibizumab, bevacizumab, and VEGF trap bind and sequester VEGF, preventing it from binding and activating VEGF receptor. Inhibitors of VEGF receptor tyrosine kinases prevent transduction of the VEGF binding signal. Small interfering RNA molecules prevent translation of VEGF (bevasiranib) or VEGF receptor-I (Sirna-027). Squalamine interferes with the function of various ion transport channels, the activity of which is required for angiogenesis. Double dotted lines represent cellular plasma membranes and the single dotted line represents nuclear membrane.

$4.3 \%$ (0.5\% group) for the ranibizumab groups (ANCHOR). Although some might consider these data to demonstrate a high level of safety, neither study was powered to evaluate safety concerns. In fact, at a 6-month interim evaluation, the SAILOR study, a phase IV evaluation of the safety and efficacy of $0.3 \mathrm{mg}$ and $0.5 \mathrm{mg}$ doses of as-needed ranibizumab reported a statistically significant increase in the rate of stroke $(0.3 \%$ compared to $1.2 \%)$ with the higher (commercially available) dose whereas for arterial thromboembolic events of myocardial infarction or vascular death, the differences between the doses were not statistically significant [personal communication, Genentech, Inc., January 24, 2007]

The burden of monthly injections of ranibizumab coupled with the appreciable risk of adverse events prompted the PIER and PrONTO studies (Rosenfeld 2006b; Schmidt-Erfurth 2007). Each study used less frequent dosing than ANCHOR and MARINA, with PIER using a fixed dosing schedule and PrONTO using an "as needed" schedule. PIER was a phase IIIb randomized, double-masked, sham-controlled study of 184 subjects who received monthly injections of ranibizumab or sham for 3 months, followed by quarterly injections. At 12 months, the sham group lost 16 letters, whereas the ranibizumab group initially gained one line but lost 0.2 letters at 12 months (Schmidt-Erfurth 2007). Although the study did not include a monthly injection of ranibizumab arm, comparison to ANCHOR and MARINA data would suggest inferiority with the PIER dosing schedule.

The PrONTO study was an open label study of 40 eyes treated with 3 consecutive monthly injections of $0.5 \mathrm{mg}$ ranibizumab followed by further injections based on loss of 5 letters visual acuity or increase of $100 \mu \mathrm{m}$ of central retinal thickness. Through 1 year, patients required an average of 
5.6 injections, $35 \%$ gained 3 or more lines, and 95\% lost fewer than 3 lines of vision (Rosenfeld 2006b). Although the criteria for re-treatment have not been systematically evaluated, and some clinicians would support treating based on other factors than those evaluated in PrONTO, decreasing the number of required injections would substantially reduce the burden of AMD treatment on patients.

Bevacizumab is a full-length antibody with similar properties to ranibizumab, and is approved for systemic use in some solid tumours and is therefore available for off-label use in the treatment of AMD-related CNV (Hurwitz 2004). An open-label uncontrolled clinical study of intravenous infusion of bevacizumab ( $5 \mathrm{mg} / \mathrm{kg})$ at baseline with $1-2$ repeated doses at 2 -week intervals in 18 patients reported a statistically significant median gain of 14 letters and decrease of OCT thickness from 379 to $255 \mu \mathrm{m}$ (Moshfeghi et al 2006). The only significant ocular or systemic adverse event was hypertension, which occurred or worsened in 10 patients and was readily treated with oral medications.

Concerns about thromboembolic events with use of intravenous bevacizumab in the treatment of cancer prompted investigators to use bevacizumab intravitreally. Multiple retrospective studies have reported on the use of $1.25 \mathrm{mg}$ doses of intravitreal bevacizumab, citing three or more lines of vision improvement in $38.3 \%$ (Spaide et al 2006) to $44 \%$ (Rich et al 2006) of treated patients and median gain of 15 letters (Rich et al 2006) to 20 letters (Avery et al 2006) at 8-12 weeks. One prospective study of monthly injections of $2.50 \mathrm{mg}$ bevacizumab reported median gain of 6 lines of vision and normalization of central retinal thickness from 350 to $211 \mu \mathrm{m}$ using optical coherence tomography (OCT) (Bashshur et al 2006). Although, the OCT data in these reports are compelling; the visual acuity data did not employ Early Treatment for Diabetic Retinopathy Study (ETDRS) protocol visual acuities and as such may not accurately reflect visual acuity improvement in these patient series.

In each of the reports on intravitreal bevacizumab, negligible adverse events were noted. This was an important finding since numerous concerns were raised with the intravitreal injections of humanized antibody such as the inciting of intraocular inflammation or the promotion of systemic thromboembolic side effects. Acknowledging the bias inherent in a survey based on self-reporting, an internet survey of adverse events of 3810 intravitreal injections in 3034 patients following intravitreal bevacizumab injections reported low rates of treatment-related and drug-related adverse events, citing rates of $0.03 \%$ for endophthalmitis and $0.1 \%$ for all forms of cerebrovascular events (Fung et al 2006). Concerns regarding the durability of compounded bevacizumab have been put to rest by in vitro studies of VEGF binding following refrigeration or freezing for up to 6 months (Bakri et al 2006).

At this time, efficacy data are superior for ranibizumab than bevacizumab, and each has demonstrated reasonable safety, with the exception of concern for increased rates of stroke demonstrated by SAILOR. In an effort to clarify these issues, the National Eye Institute has agreed to sponsor a multi-centre trial comparing ranibizumab to bevacizumab with fixed monthly versus variable dosing schedules. The Comparison of Age-related Macular Degeneration Treatment Trial (CATT) is scheduled to begin enrolling patients in the fall of 2007. Until this question can be answered by the CATT, we will be forced to treat patients with medication availability and financial feasibility issues in mind. The September, 2006 Preferences and Trends (PAT) survey, administered by the American Society of Retina Specialists (ASRS), in which the response rate was $23.57 \%$ of 1667 ASRS members demonstrated that $34.70 \%-41.75 \%$ would recommend bevacizumab for the treatment of subfoveal CNV and $33.42 \%-41.75 \%$ would recommend ranibizumab. (American Society of Retina Specialists 2007) A follow-up mini survey of the same population of retina specialists ( $n=276$ responders) specified whether the hypothetical patient was covered by Medicare with or without secondary insurance coverage, without which patients in the United States would be responsible for $20 \%$ of the medication bill, or approximately US\$400 per injection (American Society of Retina Specialists 2007). In this survey, 53.11\% would recommend bevacizumab for patients with secondary insurance, increasing to $77.01 \%$ for patients without secondary insurance.

\section{VEGF trap}

The VEGF trap (Regeneron Pharmaceuticals, Inc., Tarrytown, NY, USA) is a fusion protein of portions of VEGF receptor 1 and 2 and the Fc region of human $\operatorname{IgG}$ which binds all VEGF isoforms and does so more tightly than other available VEGF binding agents. The Clinical Evaluation of Antiangiogenesis in the Retina (CLEAR) study was a randomized, double-masked, ascending dose, placebo-controlled phase I trial of 18 patients with neovascular AMD who received either placebo or 1 of 3 systemic doses of intravenous VEGF trap $(0.3,1.0$, and $3.0 \mathrm{mg} / \mathrm{kg}$ ) (Nguyen et al 2006). The study found a dose-dependent increase in systemic blood pressure, which was clinically significant above the $1.0 \mathrm{mg} / \mathrm{kg}$ dose and further studies of systemic VEGF trap were halted. CLEAR IT-1 was a phase I dose escalation study of a single 
intravitreal injection of multiple doses VEGF trap (0.05, $0.15,0.5,1,2$, and $4 \mathrm{mg}$ ). At 6 weeks, mean gain in visual acuity was 4.8 letters and mean OCT central retinal thickness decreased from 298 to $208 \mu \mathrm{m}$ (Nguyen et al 2006). The potential benefit of VEGF trap is a sustained effect compared to single injections of other VEGF-binding agents, although this has not been demonstrated in a head-to-head trial. A phase II VEGF trap study (CLEAR-AMD) is currently in the process of enrolling patients.

\section{Small interfering RNA}

The 2006 Nobel Prize in Physiology or Medicine was awarded to Andrew Fire and Craig Mello for their work in RNA interference, the process by which small interfering RNA (siRNA) molecules inactivate messenger RNA, thereby suppressing RNA translation. For clinical use, these drugs are administered as double-stranded RNA molecules that are imported across the cellular membrane and processed by an enzyme, Dicer, which shortens the siRNA to 21-24 nucleotides. The processed siRNA is incorporated into a RNA-induced silencing complex (RISC), which, when activated, binds complementary mRNA and digests it. This allows a single molecule of siRNA to degrade multiple copies of mRNA.

The first drug to employ this mechanism in the treatment of neovascular AMD is bevasiranib (formerly Cand5, Acuity Pharmaceuticals, Philadelphia, PA) and is targeted against VEGF mRNA. The Cand5 Anti-VEGF RNA Evaluation (CARE) study was a phase II study of 3 doses of bevasiranib $(0.2,1.5$, and $3.0 \mathrm{mg})$ injected intravitreally 6 weeks apart $(n=127$ eyes). At 12 weeks after the initial injection, mean loss of vision was 4.1 letters ( $0.2 \mathrm{mg}$ dose), 6.9 letters $(1.5 \mathrm{mg}$ dose), or 5.8 letters (3.0 mg dose), with 71.8-79.4\% losing less than 3 lines. Adverse events included stroke $(0.8 \%)$, arrhythmia $(0.8 \%)$, and hypertension $(5.5 \%)$ (Tolentino 2006). Compared to improvement in vision seen with other therapies, including ranibizumab, bevacizumab, and VEGF trap, the vision loss in these patients does not bode well for the use of bevasiranib as monotherapy. By targeting a relatively upstream component of the VEGF pathway, it is currently considered that the use of siRNA may have a delayed effect in influencing disease processes. The recent FDA approval of ranibizumab may prompt a design change in the phase III study of bevasiranib to include injection of a VEGF-binding agent at baseline. The combination of VEGF binding by ranibizumab or bevacizumab combined with the mRNA interference of bevasiranib has the theoretic advantage of preventing further vision deterioration by immediately binding existent VEGF while interfering with the upstream production of VEGF.

A second siRNA drug, sirna-027 (Sirna Therapeutics, San Francisco, CA), directed against VEGF receptor 1 (VEGFR1), has demonstrated efficacy in animal models (Shen et al 2006) and reasonable safety in a Phase I trial and is undergoing phase II evaluation currently.

\section{VEGF receptor tyrosine kinase inhibition}

A further method of inhibiting the effect of increased VEGF within the eye with CNV is to inhibit the tyrosine kinase activity of VEGF receptors. Vatalanib ${ }^{\circledR}$ (formerly PTK-787, Novartis International AG, Basel, Switzerland) is a potent inhibitor of all known VEGF receptor tyrosine kinases, VEGFR1 (sFlt-1), VEGFR2 (KDR), and VEGFR3 (Flt-4). The use of vatalanib is an attractive alternative to intravitreally or intravenously injected medications because of its satisfactory oral bioavailability. Preclinical data have demonstrated inhibition of experimental retinal and choroidal neovascularisation (Maier et al 2005). Clinical studies in healthy individuals have shown no serious adverse events and adverse events from the use of vatalanib in patients with solid and hematologic malignancies have included nausea/vomiting, fatigue, dizziness, diarrhoea, and hypertension (Joondeph et al 2006). The Study of Vatalanib and Photodynamic Therapy with Verteporfin in Patients With Subfoveal Choroidal Neovascularization (CNV) Secondary to Age-related Macular degeneration (ADVANCE) is currently enrolling for a phase I/II comparison of PDT to PDT/vatalanib.

\section{PEDF}

Pigment epithelial-derived growth factor (PEDF) is a factor with neurotrophic, neuroprotective, and antiangiogenic properties (Steele et al 1993; Mori et al 2002). The potential benefit of PEDF in preventing damage due to neovascular AMD lies in its multifaceted protection of the retina and retinal pigment epithelium and inhibition of angiogenesis. CDNA encoding human PEDF has been shown to inhibit ocular neovascularization when introduced into the vitreous and subretinal space of animal models via an adenoviral vector (AdPEDF.11, GenVec, Inc., Gaithersburg, MD, USA) (Imai et al 2005). A phase I study of AdPEDF.11 in 28 patients demonstrated no dose-limiting toxicity and suggested that its anti-angiogenic effect lasts for months (Campochiaro et al 2006). Furthermore, therapy does not seem to be associated with a systemic immune response, thereby 
theoretically allowing for repeat injections (Hamilton et al 2006). The sustained effect and repeatability of this therapy is attractive approach given the relatively short duration of anti-VEGF agents.

\section{Squalamine lactate}

Squalamine lactate (Evizon ${ }^{\circledR}$, Genaera Corporation, Plymouth Meeting, PA) is an anti-angiogenic amino sterol derived from cartilage of the dogfish shark, Squalus acanthus. Its mechanism of action includes blockade of cell membrane ion transporters that regulate cell function by controlling $\mathrm{pH}$ and metabolism. When bound to calmodulin, squalamine also blocks the action of VEGF and integrin expression, thereby inhibiting angiogenesis. Squalamine is ineffective when administered intravitreally and therefore requires intravenous dosing. However, systemic dosing has yielded promising results in rats (Ciulla et al 2003) as well as humans (Kaiser 2007). In a phase I/II clinical trial of 40 patients who had received 25 or $50 \mathrm{mg} / \mathrm{m} 2$ weekly for 4 weeks, no patients lost vision and $26 \%$ gained 3 or more lines. Genaera has abandoned this product and is no longer in clinical development.

\section{Anecortave acetate}

Anecortave acetate has also been used in patients with AMD-related CNV. In these patients, Anecortave acetate produced similar visual acuity results to PDT with verteporfin in the C-01-99 study (Slakter et al 2006). With improved therapies and outcomes, anecortave acetate is not appropriate monotherapy for active CNV. However, the NEI is sponsoring the BRIDGE study that will evaluate combination therapy of anecortave acetate and ranibizumab.

\section{Vitreoretinal surgery}

The suggestion that surgical removal of CNV before the development of subretinal fibrosis would allow for reapposition of healthy RPE and photoreceptors, thereby improving visual acuity is an attractive one. Multiple techniques and modifications have been tried to improve visual acuity outcomes in patients with $\mathrm{CNV}$, including submacular surgical removal of CNV (Hawkins et al 2004), pneumatic displacement of large subretinal haemorrhage (Hassan et al 1998), and macular translocation (deJuan et al 1998; Mruthyunjaya et al 2004). To date, none of these therapies has proven effective, and with rare exception, none are appropriate primary treatment strategies for AMDassociated $\mathrm{CNV}$.

\section{Combination therapy}

As with many therapies, which have been borrowed from oncology for use in the treatment of neovascular AMD, the concept of "induction and maintenance" is one employed in several combined management approaches in an effort to improve therapeutic efficacy and reduce treatment frequency. As indicated previously, PDT has been implicated in having the undesirable observation of increasing inflammation and VEGF levels (Schmidt-Erfurth et al 2003). By combining treatment modalities, an opportunity exists to refine the blockade of angiogenesis and vascular permeability. For example combination of PDT, intravitreal anti-VEGF agent and steroid could in theory allow for blockade of $\mathrm{CNV}$ at multiple levels. The FOCUS study is a phase I/II trial comparing as-needed dosing of verteporfin followed by monthly dosing of either ranibizumab or sham injection. At 2 years, the ranibizumab/PDT group gained a mean of 4.6 letters whereas the sham/PDT group lost a mean of 7.8 letters. The number of treatments through 2 years averaged 1.4 in the ranibizumab/PDT group compared to 4.0 in the sham/PDT group (Heier, Antoszyk, et al 2006; Heier, Boyer, et al 2006).

In a prospective, non-comparative, interventional case series, 104 patients underwent triple therapy using intravitreal dexamethasone $(800 \mu \mathrm{g})$ and bevacizumab $(1.5 \mathrm{mg})$ administered within a mean of 16 hours after PDT (Agustin et al 2007). All 104 patients received one triple therapy cycle while 5 patients received a second triple treatment due to remaining CNV activity. The triple therapy was complemented in 18 patients $(17.3 \%)$ by an additional intravitreal injection of bevacizumab. The mean follow-up period was 40 weeks (range, 22-60 weeks). Mean increase in visual acuity was 1.8 lines $(\mathrm{p}<0.01)$. Mean decrease in retinal thickness was 182 micrometers $(p<0.01)$. No serious adverse events were observed. The authors concluded that triple therapy results in significant and sustained visual acuity improvement after only one cycle of treatment in patients with AMD associated CNV. In addition, the therapy offered a good safety profile and potentially lower cost compared with therapies that must be administered more frequently, and convenience for patients (Agustin et al 2007). The PDT was performed with a reduced time of light delivery (70 seconds) in an effort to theoretically reduce choroidal damage (Michels et al 2006).

The Neovascular Age-related macular degeneration, Periocular corticosteroids and Photodynamic therapy (NAPP) trial evaluated 67 patients with AMD and subfoveal $\mathrm{CNV}$. Thirty-four patients were given a single periocular 
injection of corticosteroid, followed immediately by PDT with verteporfin, and 33 patients were given PDT alone. No difference in visual acuity or angiographic leakage between the groups was observed at 6 months (NAPP Trial Research Group et al 2007).

Several other studies are combining therapeutic modalities, including the BRIDGE study (ranibizumab plus anecortave acetate), PROTECT study (ranibizumab plus PDT with verteporfin), VISION phase IV study (pegaptanib plus PDT) are currently underway.

\section{Future directions}

Another target of angiogenesis has been through nonVEGF pathways, including bioactive lipids. Sphingomab (Lpath Inc., San Diego, CA) is a monoclonal antibody targeted against sphingosine-1-phosphate, which has been implicated in angiogenesis, scar formation, and inflammation (Sabbadine 2006). Studies have been very preliminary, but the reminder that VEGF is not the only contributor to angiogenesis is important, and may play a further role in combination therapy.

Encapsulated Cell Technology (ECT), developed by Neurotech, Lincoln, RI, involves implantation into the vitreous cavity of a small semi-permeable polymer capsule. The capsular implant is lined with cultured cells that have been engineered to secrete certain proteins or peptides. The initial studies of ECT in humans have been phase I trials of ECT containing modified human retinal pigment epithelial cells (ARPE-19), programmed to secrete ciliary neurotrophic factor (CNTF) in the treatment of retinitis pigmentosa and non-neovascular AMD (Tao et al 2002; Sieving et al 2006). Assuming that these capsules demonstrate immune privilege, ECT allows for theoretically sustained low-dose delivery of a single or combination of proteins or other cellular products into the vitreous cavity.

Rather than replacing specific defective genes or supplying deficient proteins, some have advocated replacing entire cell lines and tissues. Although not yet ready for human trials, stem cell transplantation and retinal pigment epithelium transplantation are enticing goals for the management of chronic blinding diseases (Francis et al 2003). Significant challenges with these therapeutic modalities include identifying pluripotent cells, controlling their differentiation and understanding the relationships between modified cells and the immune system.

Recent advances in the understanding of the relationship between genetic susceptibility and AMD have raised new questions regarding the influence of immunity on the occurrence of CNV. One example of this is the recent association between complement factor $\mathrm{H}$ haplotypes and AMD (Edwards et al 2005). Further understanding will allow for genetic testing and identification of individuals at high risk for $\mathrm{CNV}$ and those appropriate for intensive prophylactic therapies.

\section{Conclusion}

In the last 3 years, the tertiary intervention for AMD-related $\mathrm{CNV}$, the leading cause of irreversible severe vision loss in AMD, has shifted from a predominantly laser based treatment approach to a more targeted pharmacotherapeutic approach. We have determined that pharmacotherapy is superior to laser based treatment in many patients with AMD-related CNV, allowing for better outcomes in visual acuity and retinal anatomy and has made treatment available to neovascular AMD patients who were previously poor candidates for laser-based therapy.

In this time, we have learned also that non-selective VEGF blockade by agents like ranibizumab and bevacizumab appears more efficacious in the short-term treatment of AMDassociated CNV than the use of selective VEGF blockade by agents like pegaptanib. At this juncture, caution still needs to be exercised, as the long-term risks of non-selective VEGF blockade are entirely unknown. Given the potential neuroprotective role of VEGF, in theory, complete and sustained VEGF blockade might result in long-term vision loss in AMD-related CNV.

The use of pharmacologic agents as monotherapy has allowed patients to recover vision faster than with previous treatment modalities but the effects are frequently, but not always, short-lived. A sustained beneficial effect has only been shown in treatment schedules requiring frequent intravitreal injections. As our understanding of the pathophysiologic mechanism of angiogenesis and the pharmacodynamics of anti-angiogenic agents improve, we have the opportunity to refine our treatment approach. The use of combination therapy, involving manipulation of multiple aspects of the angiogenesis cascade, is being investigated in patients with AMD-related CNV. Providing rapid and sustained improvement in the vision and function while reducing the risks and treatment burden of administering pharmaco-monotherapy may be the way of the very near future. While pharmacotherapy has help tremendously in the care of these patients with VEGF-mediated disease, long-term goals in the management of AMD will also need to address other sequelae such as vision-limiting macular ischemia, atrophy, and subretinal fibrosis in those patients 
with disease non-responsive to anti-VEGF agents or those patients with inactive but advanced disease. In addition, further investigations aimed at preventing the progression of both the neovascular and non-neovascular forms of the disease prior to the onset of vision loss will be instrumental in affording patients to maintain a better quality of life in this period of increasing life expectancy.

\section{Acknowledgments Grant support}

Supported by an unrestricted grant from Research to Prevent Blindness, NY. This funding organization had no part in the preparation of this manuscript.

\section{Proprietary Interest}

The authors have no proprietary interest in the products or procedures mentioned in this manuscript. This manuscript cites the use of drugs not approved by the United States Food and Drug Administration.

\section{References}

Adamis AP, Shima DT. 2005. The role of vascular endothelial growth factor in ocular health and disease. Retina, 25:111-18.

Age-Related Eye Disease Study Research Group. 2001. A randomized, placebo-controlled, clinical trial of high-dose supplementation with vitamins $\mathrm{C}$ and $\mathrm{E}$, beta carotene, and zinc for age-related macular degeneration and vision loss: AREDS Report No. 8. Arch Ophthalmol, 119:1417-36.

Alpha-Tocopherol, Beta Carotene Cancer Prevention Study Group. 1994. The effect of vitamin $\mathrm{E}$ and beta carotene on the incidence of lung cancer and other cancers in male smokers. N Engl J Med, 330:1029-35.

Ambati J, Ambati BK, Yoo SH, et al. 2003. Age-related macular degeneration: etiology, pathogenesis, and therapeutic strategies. Survey of Ophthalmol, 48:257-93.

American Society of Retina Specialists. Preferences and Trends Survey [online]. Accessed March 4, 2007. URL: http://www.asrs.org.

Agustin AJ, Puls S, Offermann I. 2007. Triple therapy for choroidal neovascularization due to age-related macular degeneration: Verteporfin PDT, Bevacizumab, and Dexamethasone. Retina, 27:133-40.

Avery RL, Pieramici DJ, Rabena MD, et al. 2006. Intravitreal bevacizumab $\left(\right.$ Avastin $\left.^{\circledR}\right)$ for neovascular age-related macular degeneration. Ophthalmology, 113:363-72.

Bakri SJ, Snyder MR, Pulido JS, et al. 2006. Six-month stability of bevacizumab (Avastin ${ }^{\circledR}$ ) binding to vascular endothelial growth factor after withdrawal into a syringe and refrigeration or freezing. Retina, 26:519-22.

Bashshur ZF, Bazarbachi A, Schakal A, et al. 2006. Intravitreal bevacizumab for the management of choroidal neovascularization in age-related macular degeneration. Am J Ophthalmol, 142:141-3.

Brown DM, Kaiser PK, Michels M, et al. 2006. Ranibizumab versus verteporfin for neovascular age-related macular degeneration. $N$ Engl J Med, 355:1432-44.

Campochiaro PA, Nguyen QD, Shah SM, et al. 2006. Adenoviral vectordelivered pigment epithelium derived factor for neovascular age-related macular degeneration: results of a phase I clinical trial. Human Gene Therapy, 17:67-176.

Chen Y, Wiesmann C, Fuh G, et al. 1999. Selection and analysis of an optimized anti-VEGF antibody: crystal structure of an affinity-matured Fab in complex with antigen. $J$ Mol Biol, 293:865-81.
Ciulla TA, Criswell MH, Danis RP, et al. 2003. Squalamine lactate reduces choroidal neovascularization in a laser-injury model in the rat. Retina, 23:808-14.

deJuan E Jr, Loewenstein A, Bressler NM, et al. 1998. Translocation of the retina for management of subfoceal choroidal neovascularization II: a preliminary report in humans. Am J Ophthalmol, 125:635-46.

Edwards AO, Ritter R III, Abel KJ, et al. 2005. Complement factor $\mathrm{H}$ polymorphism and age-related macular degeneration. Science, 308:421-4.

Eye Diseases Prevalence Research Group. 2004. Prevalence of agerelated macular degeneration in the United States. Arch Ophthalmol, 122:564-72.

Ferrara N. 2004. Vascular endothelial growth factor: Basic science and clinical progress. Endocr Rev, 25:581-611.

Ferrara N, Hillan KJ, Gerer HP, et al. 2004. Discovery and development of bevacizumab, and anti-VEGF antibody for treating cancer. Nat Rev Drug Discov, 3:391-400.

Ferris FL, Davis MD, Clemmons TE, et al. 2005. A simplified severity scale for age-related macular degeneration: AREDS report no. 18. Arch Ophthalmol, 123:1570-4.

Francis PJ, Stout JT. 2003. Gene therapy and control of angiogenesis. Ophthalmol Clin North Am, 16:575-82.

Fung AE, Rosenfeld PJ, Reichel EZ. 2006. The International Intravitreal Avastin $^{\circledR}$ Safety Survey: using the internet to assess drug safety worldwide. Br J Ophthalmol, 90:1344-9.

Gragoudas ES, Adamis AP, Cunningham ET, et al. 2004. Pegaptanib for neovascular age-related macular degeneration. $N$ Engl $\mathrm{J} \mathrm{Med,}$ $351: 1805-16$.

Green WR, Enger C. 1993. Age-related macular degeneration histopathologic studies. The 1992 Lorenz E Zimmerman Lecture. Ophthalmology, 100:1519-35.

Hamilton MM, Brough DE, McVey D, et al. 2006. Repeated administration of adenovector in the eye results in efficient gene delivery. Invest Ophthalmol Vis Sci, 47:299-305.

Hassan AS, Johnson MW, Regillo CD, et al. 1998. Management of submacular hemorrhage with intravitreal tPA injection and pneumatic displacement. Onvest Ophthalmol Vis Sci, 39(Suppl):227.

Hawkins BS, Bressler NM, Miskala PH, et al. 2004. Surgery for subfoveal choroidal neovascularization in age-related macular degeneration: ophthalmic findings: SST report no. 11. Ophthalmology, 111:1967-80.

Heier JS, Antoszyk AN, Pavan PR, et al. 2006. Ranibizumab for treatment of neovascular age-related macular degeneration: a phase I/II multicenter, controlled, multidose study. Ophthalmology, 113:642.e1-4.

Heier JS, Boyer DS, Ciulla TA, et al. 2006. Ranibizumab combined with verteporfin photodynamic therapy in neovascular age-related macular degeneration: year 1 results of the FOCUS study. Arch Ophthalmol, 124:1532-42. Erratum in: Arch Ophthalmol, 2007 Jan; 125:138

Hurwitz H, Fehrenbacher L, Novotny W, et al. 2004. Bevacizumab plus irinotecan, fluorouracil, and leucovorin for metastatic colorectal cancer. N Engl J Med, 350:2335-42.

Imai D, Yoneya S, Gehlbach PL, et al. 2005. Intraocular gene transfer of pigment epithelium-derived factor rescues photoreceptors from lightinduced cell death. J Cell Physiol, 202:570-8.

Joondeph BC. 2006. ADVANCE: Study of Vatalanib in Patients with Subfoveal Choroidal Neovascularization Secondary to Age-related Macular Degeneration. Retina Society/Club Jules Gonin, annual meeting. October 2006.

Kaiser PK. 2007. Verteporfin photodynamic therapy and anti-angiogenic drugs: potential for combination therapy in exudative age-related macular degeneration. Curr Med Res Opin, 23:477-87. Review.

Keyt BA, Berleau LT, Nguyen HV, et al. 1996. The carboxyl-terminal domain (111-165) of vascular endothelial growth factor is critical for its mitogenic potency. J Biol Chem, 271:7788-95.

Klein R, Klein BEK, Knudtson MD, et al. 2006. Prevalence of age-related macular degeneration in 4 racial/ethnic groups in the Multi-ethnic Study of Atherosclerosis. Arch Ophthalmol, 113:373-80. 
Maier P, Unsoeld AS, Junker B, et al. 2005. Intravitreal injection of specific receptor tyrosine kinase inhibitor PTK787/ZK222 584 improves ischaemia-induced retinopathy in a rat. Graefes Arch Clin Exp Ophthalmol, 243:593-600.

Macular Photocoagulation Study Group. 1982. Argon laser photocoagulation for senile macular degeneration. Results of a randomized clinical trial. Arch Ophthalmol, 100:912-18.

Macular Photocoagulation Study Group. 1986. Argon laser photocoagulation for neovascular maculopathy: 3-year results from randomized clinical trials. Arch Ophthalmol, 104:694-701.

Macular Photocoagulation Study Group. 1991. Laser photocoagulation of subfoveal neovascular lesions in age-related macular degeneration: results of a randomized clinical trial. Arch Ophthalmol, 109:1220-31.

Macular Photocoagulation Study Group. 1991. Subfoveal neovascular lesions in age-related macular degeneration: guidelines for evaluation and treatment in the Macular Photocoagulation Study. Arch Ophthalmol, 109:1242-57

Macular Photocoagulation Study Group. 1993. Laser photocoagulation of subfoveal neovascular lesions of age-related macular degeneration: updated findings from two clinical trials. Arch Ophthalmol, 111:1200-9.

Macular Photocoagulation Study Group. 1994. Laser photocoagulation of juxtafoveal choroidal neovascularization: 5-year results from randomized clinical trials. Arch Ophthalmol, 111:500-9.

Michels S, Hansmann F, Geitzenauer W, et al. 2006. Influence of treatment parameters on selectivity of verteporfin therapy. Invest Ophthalmol Vis Sci, 47:371-6.

Mori K, Gehlbach P, Ando A, et al. 2002. Regression of ocular neovascularization in response to increased expression of pigment epithelium-derived factor. Invest Ophthalmol Vis Sci, 43:2428-34.

Moshfeghi AA, Rosenfeld PJ, Puliafito CA, et al. 2006. Systemic bevacizumab (Avastin ${ }^{\circledR}$ ) therapy for neovascular age-related macular degeneration: twenty-four-week results of an uncontrolled open-label clinical study. Ophthalmology, 113:2002-11.

Mruthyunjaya P, Stinnett SS, Toth CA. 2004. Change in visual function after macular translocation with 360 degrees retinectomy for neovascular age-related macular degeneration. Ophthalmology, 111:1715-24.

National Institute of Health. 2007. Clinical Studies [online]. Accessed 26 February 2007. URL: http://clinicalstudies.info.nih.gov/cgi/detail. cgi?A_2006-EI-0116.html.

[NAPP Trial Research Group] Neovascular Age-Related Macular Degeneration. Periocular Corticosteroids, and Photodynamic Therapy (NAPP) Trial Research Group, Gilson MM, Bressler NM, et al. 2007. Periocular triamcinolone and photodynamic therapy for subfoveal choroidal neovascularization in age-related macular degeneration. Ophthalmology, 114:1713-21.

Nishijima K, Ng YS, Zhong L, et al. 2007. Vascular Endothelial Growth Factor-A Is a Survival Factor for Retinal Neurons and a Critical Neuroprotectant during the Adaptive Response to Ischemic Injury. Am J Pathol, 171:53-67.

Nguyen QD, Shah SM, Hafiz G, et al. 2006. CLEAR-AMD 1 Study Group A phase I trial of an IV-administered vascular endothelial growth factor trap for treatment in patients with choroidal neovascularization due to age-related macular degeneration. Ophthalmology, 113:1522-32.

Presta LG, Chen H, O'Connor SJ, et al. 1997. Humanization of an antivascular endothelial growth factor monoclonal antibody for the therapy of solid tumors and other disorders. Cancer Res, 57:4593-9.

Rakic JM, Lambert V, Devy L, et al. 2003. Placental growth factor, a member of the VEGF family, contributes to the development of choroidal neovascularization. Invest Ophthalmol Vis Sci, 44:3186-93.
Rich RM, Rosenfeld PJ, Puliafito CA, et al. 2006. Short-term safety and efficacy of intravityreal bevacizumab $\left(\right.$ Avastin $^{\mathbb{R}}$ ) for neovascular agerelated macular degeneration. Retina, 26:495-511.

Rosenfeld PJ, Brown DM, Heier JS, et al. 2006. Ranibizumab for neovascular age-related macular degeneration. N Engl J Med, 355:1419-31.

Rosenfeld PJ, Rich RM, Lalwani GA. 2006. Ranibizumab: Phase III clinical trial results. Ophthalmol Clin North Am, 19:361-72.

Sabbadine RA. 2006. Targeting sphingosine-1-phosphate for cancer therapy. Br J Cancer, 95:1131-5.

Schmidt-Erfurth U, Scholtzer-Schrehard U, Cursiefen C, et al. 2003. Influence of photodynamic therapy on expression of vascular endothelial growth factor (VEGF), VEGF receptor 3, and pigment epithelium-derived factor. Invest Ophthalmol Vis Sci, 44:4473-80.

Schmidt-Erfurth UM, Pruente C. 2007. Management of neovascular agerelated macular degeneration. Prog Retin Eye Res, 26:437-51. Epub 2007 Mar 27. Review.

Shen J, Samul R, Akiyama H, et al. 2006. Suppression of ocular neovascularization with siRNA targeting VEGF receptor 1. Gene Therapy, 13:225-34.

Sieving PA, Caruso RC, Tao W, et al. 2006. Ciliary neurotrophic factor (CNTF) for human retinal degeneration: phase I trial of CNTF delivered by encapsulated cell intraocular implants. Proc Natl Acad Sci USA, 103:3896-901.

Slakter JS, Bochow T, D'Amico DJ, et al. 2006. Anecortave acetate (15 milligrams) versus photodynamic therapy for treatment of subfoveal neovascularization in age-related macular degeneration. Ophthalmology, 113:3-13.

Spaide RF, Laud K, Fine HF, et al. 2006. Intravitreal bevacizumab treatment of choroidal neovascularization secondary to age-related macular degeneration. Retina, 26:383-90.

Spraul CW, Lang GE, Grossniklaus HE. 1996. Morphometric analysis of the choroids, Bruch's membrane, and retinal pigment epithelium in postmortem eyes with age-related macular degeneration. Invest Ophthalmol Vis Sci, 37:2724-35.

Steele FR, Chader GJ, Johnson LV, et al. 1993. Pigment epitheliumderived factor: neurotrophic activity and identification as a member of the serine protease inhibitor gene family. Proc Natl Acad Sci USA, 90:1526-30

Tao W, Wen R, Goddard MB, et al. 2002. Encapsulated cell-based delivery of CNTF reduces photoreceptor degeneration in animal models of retinitis pigmentosa. Invest Ophthalmol Vis Sci, 43:3292-8.

Tolentino M. 2006. Interference RNA technology in the treatment of CNV. Ophthalmol Clin North Am, 19:393-9, vi-vii. Review.

Treatment of Age-related Macular Degeneration with Photodynamic Therapy (TAP) Study Group. 2001. Photodynamic therapy of subfoveal choroidal neovascularization in age-related macula degeneration with verteporfin: two-year results of 2 randomized clinical trials - TAP report 2. Arch Ophthalmol, 119:198-207.

Treatment of Age-related Macular Degeneration with Photodynamic Therapy (TAP) Study Group. 2003. Effect of lesion size, visual acuity, and lesion composition on visual acuity change from baseline with and without verteporfin therapy in choroidal neovascularization secondary to age-related macular degeneration: TAP and VIP report no. 1. Am J Ophthalmol, 136:407-18.

World Health Organization. 2007. Fact sheets [online]. Accessed 4 March 2007. URL: http://www.who.int/mediacentre/factsheets/fs282/en/index. html. 